\title{
Synthesis and Photophysical Properties of Fluorene or Carbazole-Based Alternating Copolymers Containing Si and Ethynylene Units in the Main Chain
}

\author{
Naofumi Naga*, Nanae Tagaya, Haruhiko Tomoda \\ Department of Applied Chemistry, Materials Science Course, College of Engineering, Shibaura Institute of \\ Technology, Tokyo, Japan \\ Email: *nnaga@sic.shibaura-it.ac.jp
}

Received 30 January 2016; accepted 12 March 2016; published 15 March 2016

Copyright (C) 2016 by authors and Scientific Research Publishing Inc.

This work is licensed under the Creative Commons Attribution International License (CC BY). http://creativecommons.org/licenses/by/4.0/

\section{(c) (i) Open Access}

\begin{abstract}
Alternating copolymerization of 9,9-dihexyl-2,7-dibromofluorene, N-hexyl-2,7-dibromocarbazole (HCz) with diethynyldimethylsilane, diethynyldiphenylsilane, has been investigated using Sonogashira coupling reaction. Photophysical properties of the resulting copolymers were investigated with UV-Vis absorption and photoluminescence spectroscopy. All the copolymers in chloroform solution showed absorption peaks at $270-280 \mathrm{~nm}$ with shoulder peaks at around $380 \mathrm{~nm}$ derived from $\pi-\pi^{*}$ transition or intra-molecular charge transfer through $\sigma-\pi$ moiety, respectively. The chloroform solutions of the copolymers showed broad emission peaks at $415-425 \mathrm{~nm}$. The emission wave lengths of the copolymers in the solid state (cast film) detected at 360 - 385 nm were remarkably blue-shifted in comparison with those in the chloroform solutions. Hydrosilylation reaction of the copolymers with 1,4-bis(dimethylsilyl)benzene yielded networked copolymers soluble in chloroform, indicating formation of branching polymers. The chloroform solutions of the HCz-based networked copolymers showed bimodal emission derived from new highly energy states in the $\sigma-\pi$ conjugation.
\end{abstract}

\section{Keywords}

Fluorene, Carbazole, Alternating Copolymer, Si-Ethynylene, Photophysical Property, Network Polymer

\footnotetext{
${ }^{*}$ Corresponding author.
}

How to cite this paper: Naga, N., Tagaya, N. and Tomoda, H. (2016) Synthesis and Photophysical Properties of Fluorene or Carbazole-Based Alternating Copolymers Containing Si and Ethynylene Units in the Main Chain. International Journal of Organic Chemistry, 6, 20-30. http://dx.doi.org/10.4236/ijoc.2016.61003 


\section{Introduction}

A number of conjugated polymers have been developed due to their attractive features, especially phot- and electro-luminescence. One of the most useful applications of the conjugated polymers must be emission layers for organic light-emitting diodes (LEDs) [1] [2]. There are some advantages in the polymer electro-luminescence in comparison with inorganic electro-luminescence. The first is process ability to form the emission layer. The conjugated polymers with specific molecular structures show good solubility in organic solvents, and spincoating or casting of the solutions makes it possible to form thin emission layer in the LED devices. Molecular design of the conjugated polymers can improve the solubility of the polymers in conventional organic solvents, for examples, incorporation of bulky side group and/or copolymerization. The second is control of the emission wavelength by the molecular design of the polymers. The emission wavelength is correlated with the conjugation length in the polymer electro-luminescence. The shortening or extension of the conjugation length of the polymers tends to induce blue-shift or red-shift of the emission wavelength, respectively. The third is geometrical variation of the polymers, such as conjugated polymers with networked, dendritic, or branched structure.

Incorporation of $\mathrm{Si}$ atom in the main chain of the $\pi$-conjugated polymers is effective to shorten the conjugation length [3]-[14]. Kim et al. reported the incorporation of Si atom into poly(p-phenylenevinlene), which showed blue-emission [3]. Masuda et al. synthesized poly(phenylene-ethnylene) containing Si atom in the main chain [4]. They observed the emissions of the polymers derived from not only $\pi-\pi^{*}$ transition of the $\pi$-conjugation but intramolecular charge transfer through $\sigma-\pi$ conjugation. We developed fluorene- and carbazole-based alternating copolymers containing Si-vinylene units in the main chain [15] [16]. These copolymers were synthesized by alternating copolymerization of dibromofluorene or dibromocarbazole with Si containing divinyl or diallyl compounds using Mizoroki-Heck reaction with a Pd catalyst. Incorporation of Si and unsaturated vinylene units in the main chain of the conjugated polymers was effective to improve solubility in the organic solvents. The incorporation of Si or vinylene units in the $\pi$-conjugated polymers played the opposite role for their photophysical properties. That is, the Si units shorten and vinylene units extend the conjugation length. The fluoreneand carbazole-based alternating copolymers containing Si-vinylene units in the main chain showed both the blue-shift and red-shift in the absorption and luminescence peaks depend on the state of the copolymers. As the next step, we came to an idea to incorporate Si-ethynlene units in the corresponding copolymers.

The conjugated network polymers with the $\sigma-\pi$ conjugation have been synthesized by some synthetic methods [6] [17]-[19]. Neckers et al. synthesized dendritic poly(p-phenylenevinlene) containing Si-vinylene units, and reported the relationship between length of the p-phenylenevinlene unit and quantum yield [17]. Yamashita et al. synthesized $\sigma-\pi$ conjugated network polymers by a hydrosilylation reaction between dihydrosilane compounds and diethynyl/triethynyl-benzene mixture, and reported increase of the absorption and fluorescence intensities with increasing of the crosslinking density [6]. Ishikawa et al. reported synthesis of the $\sigma-\pi$ conjugated network copolymers by a crosslinking of poly[(silylene)diethnylene] with 1,4-bis(methylphenylsilyl)benzene using a hydrosilylation reaction [19]. This method is usable to synthesize the network polymers with the $\sigma-\pi$ conjugation from the fluorene- and carbazole-based copolymers having Si-ethynlene units in the main chain synthesized in this report.

This paper reports the alternating copolymerization of 9,9-dihexyl-2,7-dibromofluorene (HFl) or N-hexyl-2,7dibromocarbazole $(\mathrm{HCz})$ with diethynylene Si compounds, diethynyldimethylsilane (EMS) or diethynyldiphenylsilane (EPS), by Sonogashira coupling reaction, as shown in Scheme 1, and the photophysical properties of the resulting copolymers. We also synthesize the network polymers by a hydrosilylation reaction of the obtained copolymers with 1,4-bis(dimethylsilyl)benzene (DMSB), and study the effect of the networking on the photophysical properties in comparison with the original linear copolymers.

\section{Experimental}

\subsection{Materials}

Dichlorodimethylsilane (Aldrich Co. Ltd.), dichlorodiphenylsilane (Tokyo Chemical Industry Co. Ltd.), and tetrahydrofuran (THF) solution of ethynylmagnesiumbromide (0.5 M) (Aldrich Co. Ltd.) were purchased and used as received. Palladium(II)dichlororbis(triphenylphosphine) $\left(\mathrm{PdCl}_{2}\left(\mathrm{PPh}_{3}\right)_{2}\right)$ (Wako Pure Chemical Industries, Ltd.), CuI (Wako Pure Chemical Industries, Ltd.), triphenylphosphine $\left(\mathrm{PPh}_{3}\right)($ Wako Pure Chemical Industries, 


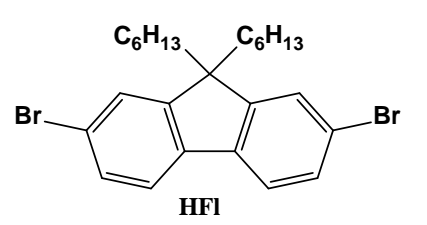

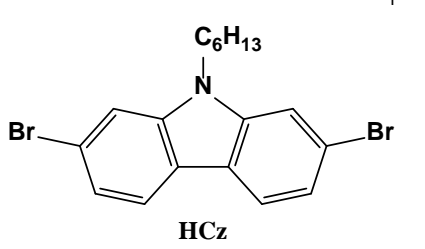
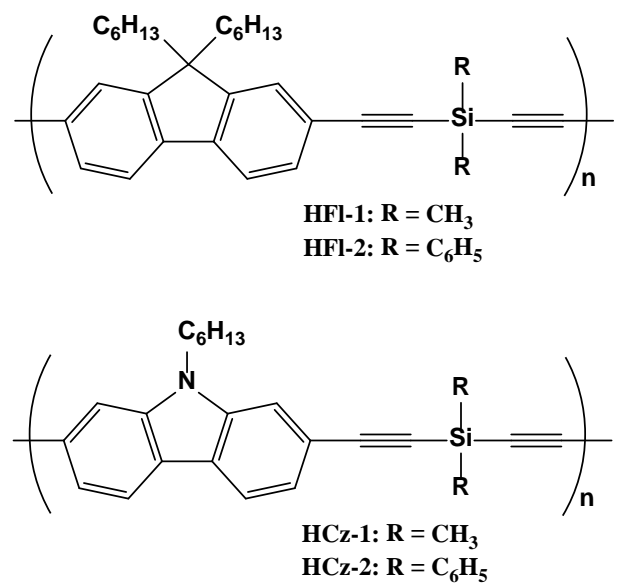

Scheme 1. Synthesis of fluorere or carbazole-based lwternating copolymers containing Si and ethynylene units in the main chain.

Ltd.), THF (dehydrate grade, Kanto Chemical Co. Ltd.), and diethylether (dehydrate grade, Kanto Chemical Co. Ltd.) were commercially obtained, and used without further purification. Triethylamine ( $\mathrm{NEt}_{3}$ ) (Kanto Chemical Co. Ltd.) was dried with $\mathrm{CaH}_{2}$ and distilled under a nitrogen atmosphere. HFl (Aldrich Co. Ltd.) was commercially obtained and used as received. $\mathrm{HCz}$ was synthesized according to the literatures [20]. Chloroform for photophysical properties analyses (Kanto Chemical Co. Ltd.) and tris(8-hydroxyquinoline)aluminum (Alq ${ }_{3}$ ) (Wako Pure Chemical Industries, Ltd.) were commercially obtained, and used without further purification. DMSB was commercially obtained from Chisso Co. Ltd., and used as received. Toluene (Kanto Chemical Co. Ltd.) was dried over calcium hydride under refluxing for $6 \mathrm{~h}$, and distilled under nitrogen atmosphere before use. Platinum-divinyltetramethyldisiloxane complex ( $\mathrm{Pt}(\mathrm{dvs})$ ) in vinyl terminated polydimethyl siloxane (Chisso Co. Ltd.) was diluted to $0.60 \mathrm{mM}$ with distilled toluene and stored under nitrogen atmosphere.

\subsection{Synthesis of EMS and EPS}

A THF solution of ethynylmagnesiumbromide $(0.5 \mathrm{M}, 80 \mathrm{~mL})$ was added dropwise to a diethylether solution $(20 \mathrm{~mL})$ of dichlorodimethylsilane, or dichlorodiphenylsilane $(0.02 \mathrm{~mol})$ at room temperature. The reaction mixture was refluxed at $40^{\circ} \mathrm{C}$ for $2 \mathrm{~h}$, and cooled to room temperature. After the precipitates were filtered off, the solution was concentrated by evaporation. The obtained product was extracted with n-pentane, and n-pentane was removed off by evaporation under reduced pressure. The obtained products were pure enough by ${ }^{1} \mathrm{H}$ NMR spectroscopy. Yields of EMS and EPS were 52\% or 65\%, respectively.

\subsection{Copolymerization}

The copolymerization was carried out in a $100 \mathrm{~mL}$ glass reactor equipped with a magnetic stirrer. $\mathrm{HFl}$ or $\mathrm{HCz}$ $(0.718 \mathrm{mmol}), \mathrm{CuI}(6.53 \mu \mathrm{mol}), \mathrm{PPh}_{3}(6.53 \mu \mathrm{mol})$ were added to the reactor under nitrogen atmosphere. EMS or EPS $(0.718 \mathrm{mmol})$, THF solution $(2.5 \mathrm{~mL})$ of $\mathrm{PdCl}_{2}\left(\mathrm{PPh}_{3}\right)_{2}(25.3 \mu \mathrm{mol})$ and $\mathrm{NEt}_{3}(0.04 \mathrm{mmol})$ were introduced to the reactor, and the copolymerization was conducted at $60^{\circ} \mathrm{C}$ for $48 \mathrm{~h}$. The copolymerization was terminated by adding a small amount of methanol. The polymer was precipitated in a large excess of methanol and recovered by filtration or decantation. The copolymer obtained was dissolved in chloroform and re-precipitated in methanol. The precipitate was recovered by filtration or decantation and dried in vacuo at $60^{\circ} \mathrm{C}$ for $6 \mathrm{~h}$.

\subsection{Synthesis of Network Copolymers}

The reaction was carried out in a $100 \mathrm{~mL}$ glass reactor equipped with a magnetic stirrer. A copolymer (0.410 mmol of repeating unit), DMSB $(0.205 \mathrm{mmol})$, and toluene solution of $\mathrm{Pt}(\mathrm{dvs})(10.4 \mu \mathrm{mol})$ were added to the reactor under a nitrogen atmosphere. The copolymerization was terminated by adding a small amount of methanol. The polymer was precipitated in a large excess of methanol and recovered by filtration. The precipitate was recovered by filtration and dried in vacuo at $60^{\circ} \mathrm{C}$ for $6 \mathrm{~h}$. 


\subsection{Analytical Procedures}

${ }^{1} \mathrm{H}$ and ${ }^{13} \mathrm{C}$ NMR spectra of the copolymers were recorded at room temperature on a JEOL-JNM-LA300 spectrometer in pulse Fourier transform mode. The sample solution was made in $\mathrm{CDCl}_{3}$ as a solvent, and the resonance of $\mathrm{CDCl}_{3}(7.24 \mathrm{ppm})$ was used as an internal reference. Molecular weight and molecular weight distribution of the copolymers were measured at $40^{\circ} \mathrm{C}$ by means of gel-permeation chromatography, SHIMADZU Prominence GPC System, using chloroform as a solvent and calibrated with standard polystyrene samples. UV-vis absorption spectroscopy was conducted with SHIMADZU UV-1600PC in a chloroform solution, $10^{-5}$ $\mathrm{mol} / \mathrm{L}$ of the repeating unit of the copolymers. Photoluminescence (PL) spectroscopy was investigated with a SHIMADZU RF-1500 in a chloroform solution, $10^{-8} \mathrm{~mol} / \mathrm{L}$ of the repeating units of the copolymer, or cast film from a chloroform solution, excited at the maximum absorption wavelength of the copolymers.

\section{Results and Discussion}

\subsection{Synthesis of Alternating Copolymers}

Copolymerization of HFl, $\mathrm{HCz}$ and EMS, EPS has been investigated with $\mathrm{PdCl}_{2}\left(\mathrm{PPh}_{3}\right)_{2}$ in THF at $60^{\circ} \mathrm{C}$ (Scheme 1). The results are summarized in Table 1. Although the molecular weights of the copolymers were relatively low, the corresponding copolymers were obtained in good yield. All the copolymers were soluble in conventional solvents such as acetone, chloroform, THF, toluene, and dimethylformamide.

\subsection{Photophysical Properties of HFl-Based Copolymers}

Photophysical properties of the HFl-based copolymers in chloroform solution were investigated with UV-vis absorption or PL spectroscopy. The UV-vis spectra of the HFlu-based copolymers in chloroform are shown in Figure 1. The copolymers showed a strong absorption peaks at $280 \mathrm{~nm}$ with broad shoulder peaks at around 370 $\mathrm{nm}$. The absorption peaks at around $370 \mathrm{~nm}$ should be derived from $\pi-\pi^{*}$ transition of the fluorene moiety, as detected in the reference polymer HFl-0. The absorption peaks at $280 \mathrm{~nm}$, which was not detected in the reference polymer HFl-0, would be induced by intramolecular charge transfer through the $\sigma$ - $\pi$ moiety in the copolymers, as previously reported [15]. All the absorption peaks of the present copolymers containing Si-ethynylene units were blue-shifted in comparison with those of the corresponding copolymers containing Si-vinylene units (HFl-i, HFl-ii) or HFlu homo polymer (HFl-0) (Scheme 2, Table 2). The blue-shift in UV-vis spectra of the

Table 1. Results of copolymerization of HFl,r HCz and EMS, EPS ${ }^{\mathrm{a}}$.

\begin{tabular}{ccccc}
\hline Sample & Monomer & Yield \% & $M_{n}^{b}$ & $M_{w} / M_{n}^{b}$ \\
\hline HFl-1 & HFl/EMS & 29 & 1900 & 1.9 \\
HFl-2 & HFl/EPS & 40 & 2400 & 2.3 \\
HCz-1 & HCz/EMS & 26 & 1300 & 3.3 \\
HCz-2 & HCz/EPS & 52 & 1700 & 3.2 \\
\hline
\end{tabular}

${ }^{\mathrm{a}} \mathrm{HFl}, \mathrm{HCz}=0.718 \mathrm{mmol}, \mathrm{EMS}, \mathrm{EPS}=0.718 \mathrm{mmol}, \mathrm{THF}=2.5 \mathrm{~mL}, \mathrm{PdCl}_{2}\left(\mathrm{PPh}_{3}\right)_{2}=25.3 \mu \mathrm{mol}, \mathrm{PPh}_{3}=6.53 \mu \mathrm{mol}, \mathrm{NEt} 3=0.04 \mathrm{mmol}, \mathrm{CuI}=6.53$ $\mu \mathrm{mol}, 60^{\circ} \mathrm{C}, 48 \mathrm{~h}$, ${ }^{\mathrm{b}}$ Determined by gel permeation chromatography using polystyrene standards.

Table 2. Photophysical properties of HFl-based copolymers containing Si-unsaturated units in the main chain ${ }^{\mathrm{a}}$.

\begin{tabular}{|c|c|c|c|c|c|}
\hline \multirow{2}{*}{ Sample } & \multicolumn{2}{|c|}{ Solution, $\lambda_{\max }(\mathrm{nm})$} & \multirow{2}{*}{$\phi_{P L}^{d}$} & \multicolumn{2}{|c|}{ Film ${ }^{\mathrm{e}}, \lambda_{\max }(\mathrm{nm})$} \\
\hline & Absorption $^{\mathrm{a}}$ & Emission $^{\mathrm{b}, \mathrm{c}}$ & & Absorption & Emission $^{\mathrm{c}}$ \\
\hline HFl-1 & $279(372)$ & 414 & 0.90 & 209 (348) & 382 \\
\hline HFl-2 & $281(376)$ & 416 & 0.21 & $210(377)$ & 386 \\
\hline $\mathrm{HFl- \textrm {i } ^ { \mathrm { f } }}$ & $411(340)$ & 460 & 0.98 & 414 & 471 \\
\hline $\mathrm{HFl}-\mathrm{ii}^{\mathrm{f}}$ & 345 & 454 & 0.95 & 342 & 466 \\
\hline $\mathrm{HFl}-0^{\mathrm{f}}$ & 377 & 414 & 0.23 & 382 & 422 \\
\hline
\end{tabular}

${ }^{\mathrm{a}}$ Evaluated in chloroform (repeating unit: $10^{-5} \mathrm{~mol} / \mathrm{L}$ ), bracket: shoulder peak, ${ }^{\mathrm{b}}$ Evaluated in chloroform (repeating unit:10 ${ }^{-8} \mathrm{~mol} / \mathrm{L}$ ), ${ }^{\mathrm{c}}$ Emission was excited at $\lambda_{\max }$ of absorption, ${ }^{\mathrm{d}}$ Quantum efficiency measured using $\mathrm{Alq}_{3}$ as a standard, ${ }^{\mathrm{e}}$ Polymer was casted from a chloroform solution (repeating unit: $\left.10^{-3} \mathrm{~mol} / \mathrm{L}\right),{ }^{\mathrm{f}} \operatorname{Ref}[15]$. 
<smiles>[R][Si]([R])(/C=C/c1ccc2c(c1)C(CCCC)(CCCC)C2)CCC</smiles>

HFl-i: $\mathbf{R}=\mathrm{CH}_{3}$ HFl-ii: $\mathrm{R}=\mathrm{C}_{6} \mathrm{H}_{5}$

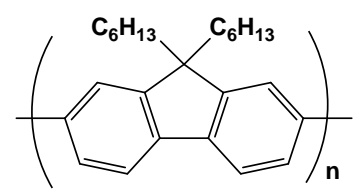

HFl-0

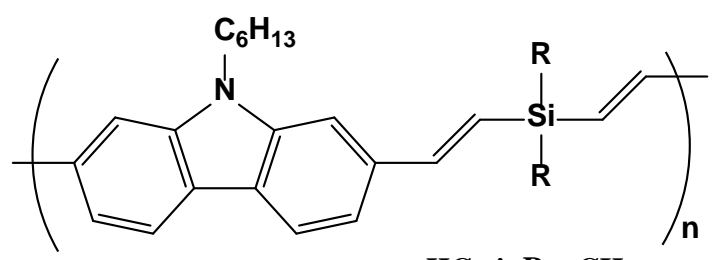

HCz-i: $\mathbf{R}=\mathrm{CH}_{3}$

HCz-ii: $\mathbf{R}=\mathrm{C}_{6} \mathrm{H}_{5}$

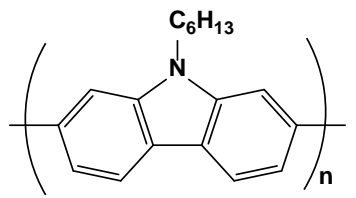

HCz-0

Scheme 2. HFl- and HCz-based (co)polymers for reference.

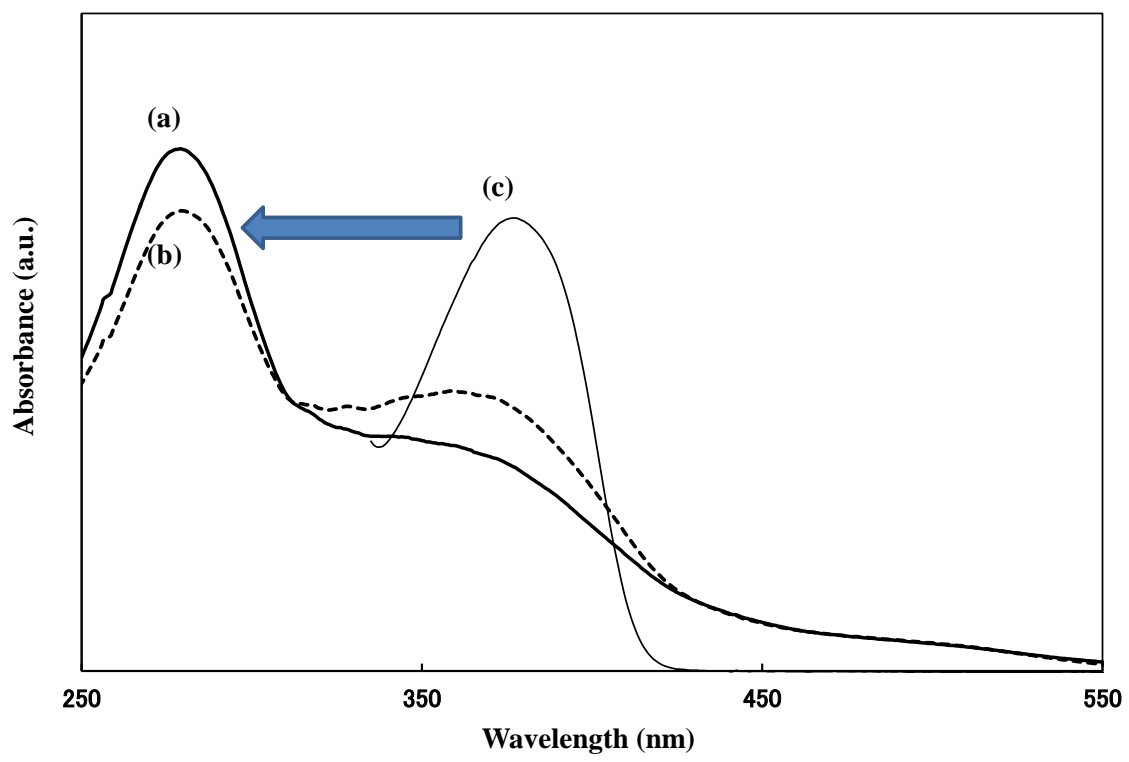

Figure 1. UV spectra of (a) HFl-1, (b) HFl-2, and (c) HFl-0 (reference) in chloroform solution, HFl unit: $10^{-5} \mathrm{~mol} / \mathrm{L}$.

present copolymers should be derived from shortening of the conjugation length by Si-ethynylene unit having short length and rigid structure.

Figure 2 shows the PL spectra of the HFl-based copolymers in chloroform. The copolymers showed broad emission peaks at around $415 \mathrm{~nm}$. The emission wavelengths of the copolymers were almost same with the HFl homo-polymer (HFl-0). One explanation of the results is that both the shortening with $\mathrm{Si}$ and extension with ethynylene units of the $\pi$-conjugation length by $\sigma-\pi$ moiety would cancel the shifts of the emission wavelength. The excitation spectra of the HFl-1, which were detected at the emission wavelength of $415 \mathrm{~nm}$, showed the maximum emission intensity with excitation wavelength of $279 \mathrm{~nm}$, which was $\lambda_{\max }$ of the absorption spectrum. The excitation with $372 \mathrm{~nm}$, which was the shoulder peak of the absorption spectrum, just induced a weak emission at $415 \mathrm{~nm}$. These results indicate that the emission at $415 \mathrm{~nm}$ should be derived from the intramolecular charge transfer through the $\sigma-\pi$ moiety. The PL quantum yields of HFl-based copolymers, 0.9 (HFl-1) and 0.2 (HFl-2), were in range those of the reference (co)polymers. The PL spectroscopy of the copolymers was also investigated in the solid state, as the cast films prepared form the chloroform solutions at room temperature. The PL spectra of the HFl-1 and HFl-2 in the solid state are shown in Figure 3. The copolymers showed broad emission peaks at $380 \mathrm{~nm}$, which was blue-shifted in comparison with that of HFl-0. Furthermore, the emission wavelengths in the solid state were blue-shifted in comparison with those in the chloroform solutions. These results 


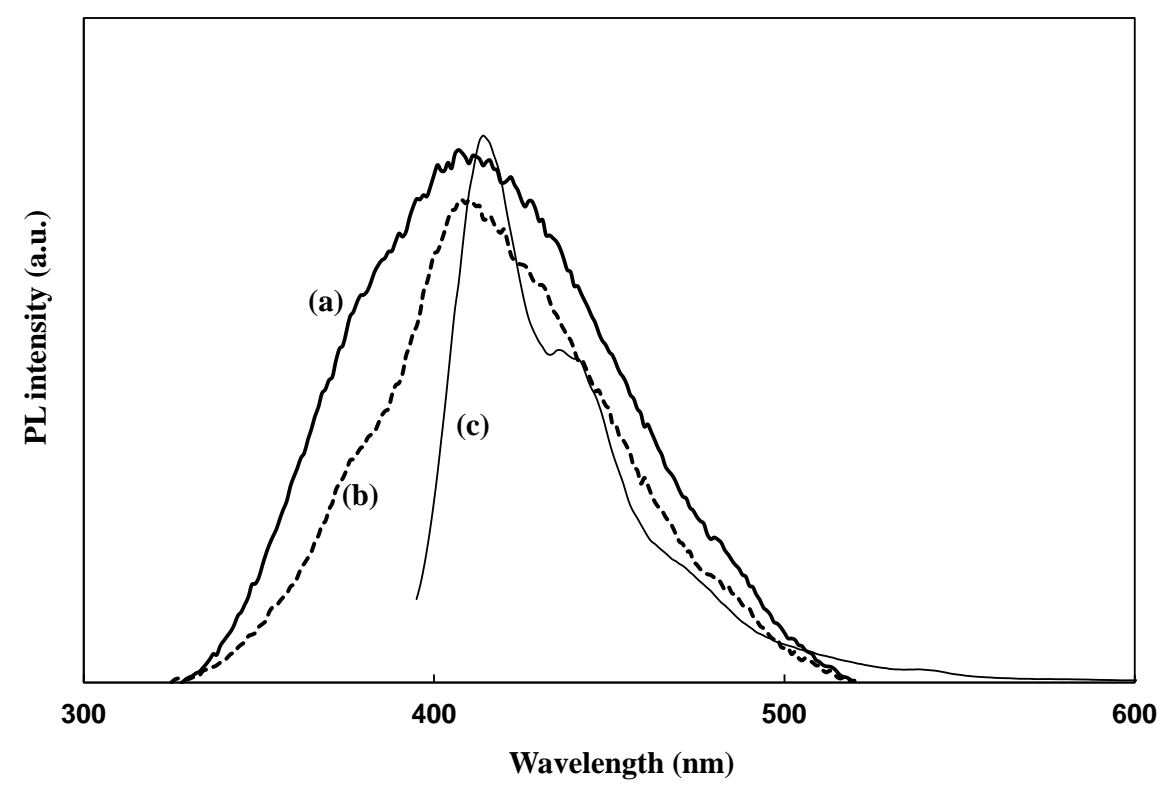

Figure 2. PL spectra of (a) HFl-1, (b) HFl-2, and (c) HFl-0 (reference) in chloroform solution, HFl unit: $10^{-8} \mathrm{~mol} / \mathrm{L}$.

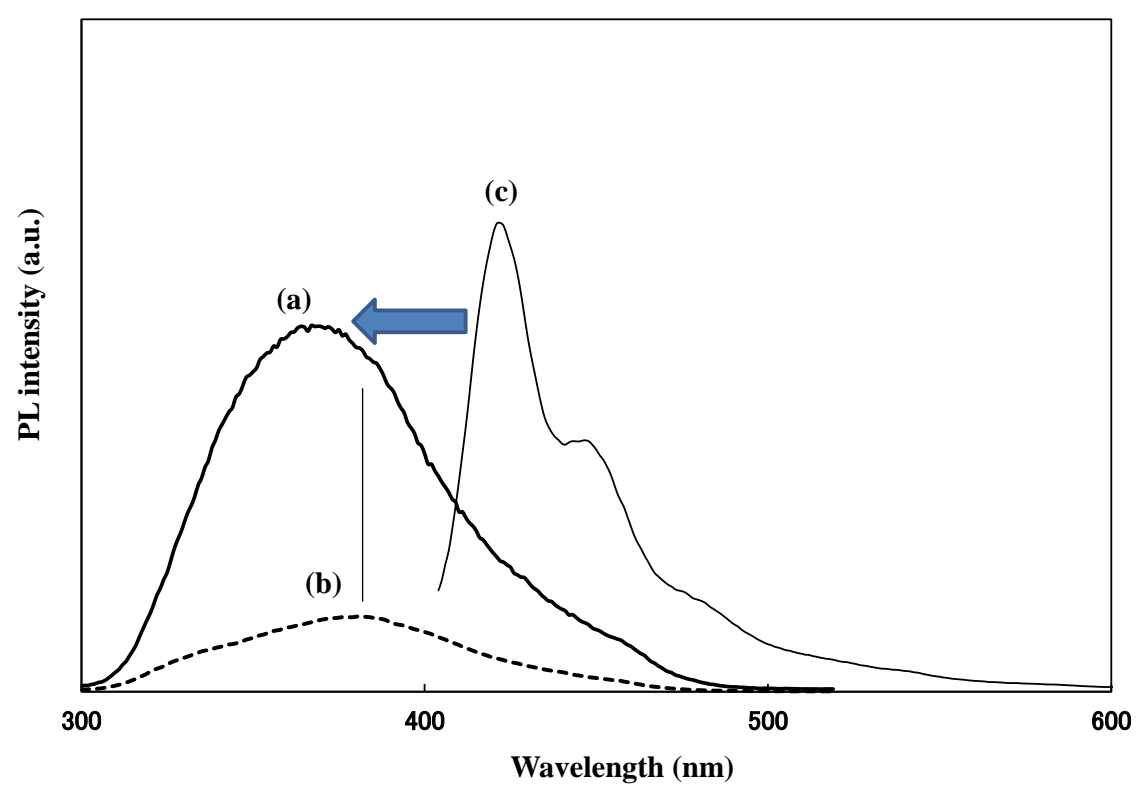

Figure 3. PL spectra of (a) HFl-1, (b) HFl-2, and (c) HFl-0 (reference) in solid state (cast film).

indicate that the aggregation of the HFl-1 and HFl-2 copolymers would form new high energy states. The reference copolymers with Si-vinylene units (HFl-i and HFl-ii) and homo-polymer HFl-0 (Scheme 2) showed the opposite tendency [15]. The Si-ethynylene units in the present copolymers should play an important role for the blue-shift of the emission wavelength in the solid state.

\subsection{Photophysical Properties of HCz-Based Copolymers}

Photophysical properties of the HCz-based copolymers in chloroform solution were studied with UV-vis absorption or PL spectroscopy. Figure 4 shows the UV-vis spectra of the HCz-based copolymers in chloroform. 
The chloroform solutions of the copolymers showed strong absorption peaks at $270 \mathrm{~nm}$ with broad shoulder peaks at around $360-380 \mathrm{~nm}$. The absorption peaks at around $360-380 \mathrm{~nm}$ should be derived from the $\pi-\pi^{*}$ transition of the carbazole moieties, as detected in the reference polymer HCz-0 [15]. The absorption peaks at $270 \mathrm{~nm}$ would be induced by the intramolecular charge transfer through the $\sigma-\pi$ moiety, as shown in the HFlbased copolymers described above. The peak intensities of the shoulder peaks of the HCz-based copolymers were higher than those of the HFl-based copolymers. The result indicates that the intramolecular charge transfer through the $\sigma-\pi$ moiety should occur frequently in the HCz-based copolymers. All the absorption peaks of the present HCz-based copolymers containing Si-ethynylene units were blue-shifted in comparison with those of the corresponding copolymers containing Si-vinylene units (HCz-i, HCz-ii) or $\mathrm{HCz}$ homo-polymer (HCz-0) (Scheme 2, Table 3). The blue-shift in UV-vis spectra of the present copolymers should be derived from shortening of the conjugation length by Si-ethynylene units, as observed in the HFl-based copolymers.

Figure 5 shows the PL spectra of the HCz-based copolymers (HCz-1 and HCz-2) in chloroform. The copolymers showed broad emission peaks at around $425 \mathrm{~nm}$. The emission wavelengths of the copolymers were red-shifted (about $10 \mathrm{~nm}$ ) in comparison with that of the $\mathrm{HCz}$ homo-polymer (HCz-0). The extension of $\pi$-conjugation length with ethynylene unit would be more effective than the shortening of it with Si by the $\sigma-\pi$ moiety in the HCz-based copolymers. The PL quantum yield of HCz-based copolymers, 0.2 (HCz-1) and 0.5 (HCz-2), were lower than the reference (co)polymers. Figure 6 shows the PL spectra of the HCz-based copolymers in the solid state. The copolymers showed broad emission peaks at $360 \mathrm{~nm}$, which were blue-shifted in comparison with that of HCz-0. The emission wavelengths in the solid state were blue-shifted in comparison with those in the chloroform solutions, as observed in the HFl-based copolymers. The reference copolymers with Si-vinylene units (HCz-i and HCz-ii) and homo-polymer HCz-0 (Scheme 2) showed the opposite tendency [15].

Table 3. Photophysical properties of HCz-based copolymers containing Si-unsaturated units in the main chain ${ }^{\mathrm{a}}$.

\begin{tabular}{|c|c|c|c|c|c|}
\hline \multirow{2}{*}{ Sample } & \multicolumn{2}{|c|}{ Solution, $\lambda_{\max }(\mathrm{nm})$} & \multirow{2}{*}{$\phi_{P L}^{d}$} & \multicolumn{2}{|c|}{ Film ${ }^{\mathrm{e}}, \lambda_{\max }(\mathrm{nm})$} \\
\hline & Absorption $^{\mathrm{a}}$ & Emission $^{\mathrm{b}, \mathrm{c}}$ & & Absorption & Emission $^{c}$ \\
\hline $\mathrm{HCz}-1$ & 267 (363) & 425 (373) & 0.19 & 267 (377) & 357 \\
\hline $\mathrm{HCz}-2$ & 268 (377) & 425 (371) & 0.48 & $268(396)$ & 360 \\
\hline $\mathrm{HCz}-\mathrm{i}^{\mathrm{f}}$ & 332 & 454 & 0.47 & 334 & 477 \\
\hline HCz-ii ${ }^{\mathrm{f}}$ & 349 & 454 & 0.94 & 349 & 482 \\
\hline $\mathrm{HCz}-0^{\mathrm{f}}$ & 373 & 414 & 0.79 & 377 & 433 \\
\hline
\end{tabular}

${ }^{\mathrm{a}}$ Evaluated in chloroform (repeating unit: $10^{-5} \mathrm{~mol} / \mathrm{L}$ ), bracket: shoulder peak, ${ }^{\mathrm{b}}$ Evaluated in chloroform (repeating unit: $10^{-8} \mathrm{~mol} / \mathrm{L}$ ), ${ }^{\mathrm{c}} \mathrm{Emission}$ was excited at $\lambda_{\max }$ of absorption, ${ }^{\mathrm{d}}$ Quantum efficiency measured using $\mathrm{Alq}_{3}$ as a standard, ${ }^{\mathrm{e}}$ Polymer was casted from a chloroform solution (repeating unit: $\left.10^{-3} \mathrm{~mol} / \mathrm{L}\right),{ }^{\mathrm{f}} \operatorname{Ref}[15]$.

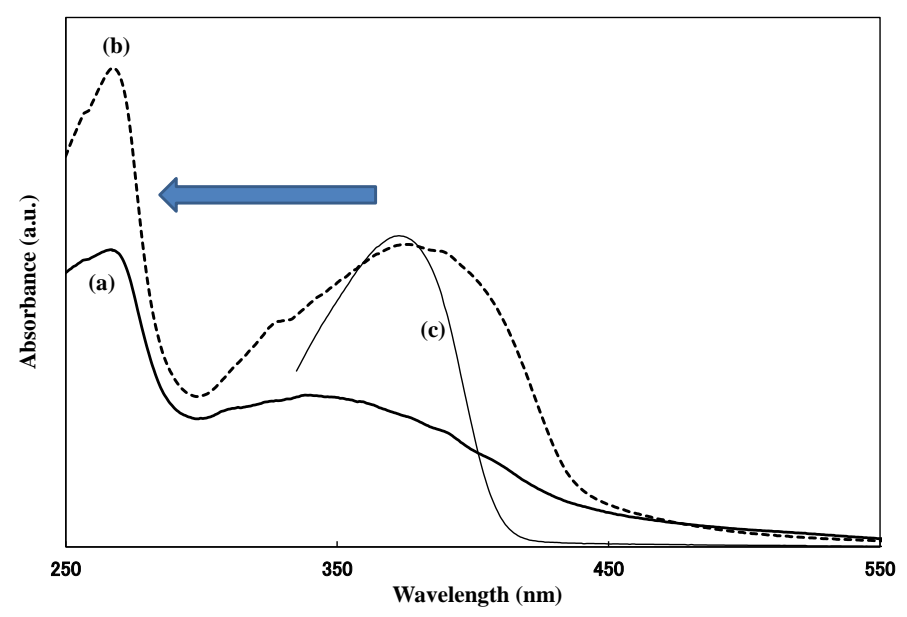

Figure 4. UV spectra of (a) HCz-1, (b) HCz-2, and (c) HCz-0 (reference) in chloroform solution, $\mathrm{HCz}$ unit: $10^{-5} \mathrm{~mol} / \mathrm{L}$. 


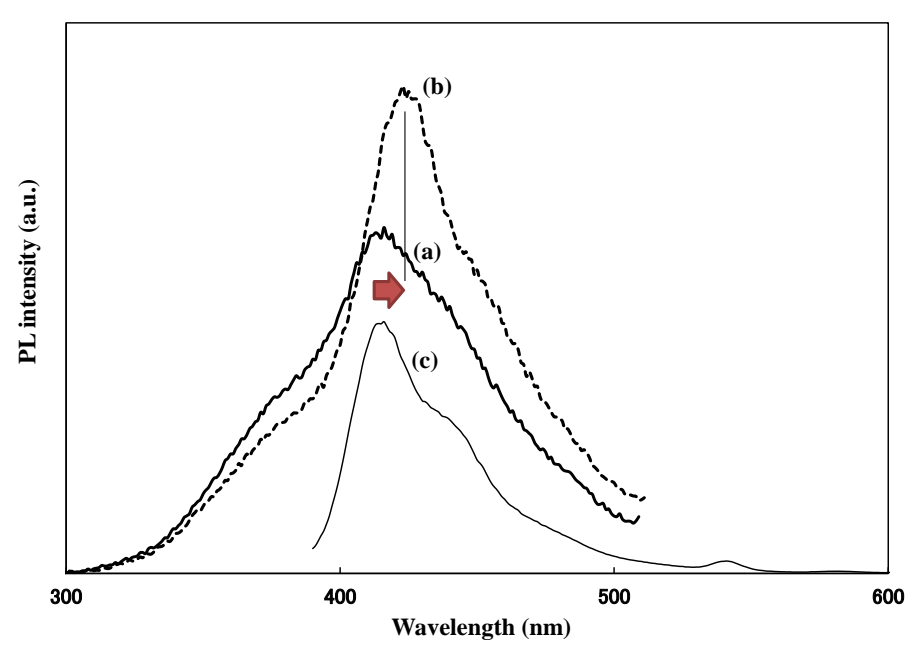

Figure 5. PL spectra of (a) $\mathrm{HCz}-1$, (b) $\mathrm{HCz}-2$, and (c) $\mathrm{HCz}-0$ (reference) in chloroform solution, $\mathrm{HCz}$ unit: $10^{-8} \mathrm{~mol} / \mathrm{L}$.

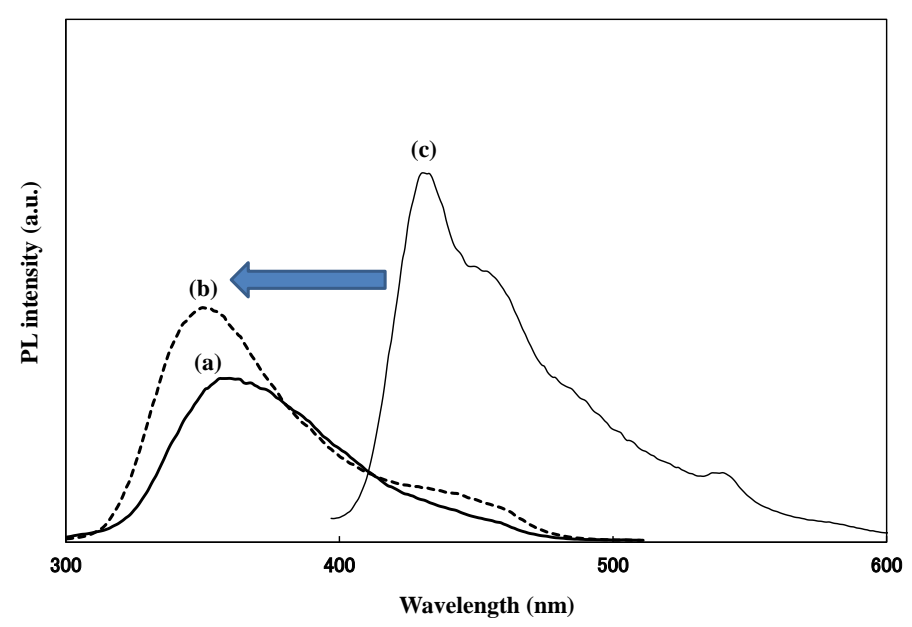

Figure 6. PL spectra of (a) HCz-1, (b) HCz-2, and (c) HCz-0 (reference) in solid state (cast film).

The results should be derived from the specific aggregation of the copolymers induced by Si-ethynylene units in the copolymers, as explained in the results of the HFl-based copolymers. The blue-shift factors, difference of the emission wavelengths in the chloroform solution and solid state, of the HCz-based copolymers (about $70 \mathrm{~nm}$ ) were higher than those of the HFl-based copolymers (about $30 \mathrm{~nm}$ ). The results indicate that the molecular structure of the $\mathrm{HCz}$ unit should be also important to form the new high energy state in the solid state. We have tried to investigate the solid structure of the copolymers by X-ray diffraction, although, we couldn't have the clear diffraction patterns of the copolymers. It remains as unsettled question what makes difference of the blue-shift factor between the HFl and $\mathrm{HCz}$ units in the copolymers. One possibility is that $\mathrm{HCz}$ units in the copolymers would effectively prevent from formation of the $\pi$-stacking, which causes red-shift of the emission wavelength, due to the electric repulsion between nitrogen atoms in the carbazole moiety.

\subsection{Synthesis and Photophysical Properties of Network Copolymers with DMSB}

The HFl and HCz based network copolymers were prepared by a hydrosilylation reaction with DMSB using $\mathrm{Pt}(\mathrm{dvs})$ catalyst, as shown in Scheme 3. The resulting network copolymers were soluble in chloroform, and insoluble part was hardly detected. The result indicates that the reaction of the copolymers with low molecular weights could not form the infinite network structure and yielded the branching copolymers. The degree of the 
branching, reaction conversion of the ethynly groups in the copolymers, was determined by ${ }^{13} \mathrm{C}$ NMR spectroscopy. The results cleared that $1 / 2$ to $2 / 3$ part of the ethynyl groups in the copolymers reacted with DMSB. The HFl and HCz-based network copolymers showed the emission peaks at round $280 \mathrm{~nm}$ and $270 \mathrm{~nm}$, respectively, as summarized in Table 4. The HFl-based network copolymers showed the almost same emission wavelengths with those of the original copolymers in chloroform. Figure 7 shows the PL spectra of HCz-based network copolymers in chloroform, and those of original copolymers for the references. The HCz-1 network copolymer showed a main emission peak at $411 \mathrm{~nm}$, which was slightly blue-shifted in comparison with that of the original polymer. In addition, a shoulder emission peak was newly detected in the network polymer at around $375 \mathrm{~nm}$. In the case of the HCz-2 network copolymer, a main emission peak was newly detected at around $372 \mathrm{~nm}$ with a shoulder peak at around $426 \mathrm{~nm}$. The excitation spectra of the HCz-2 network copolymer, detected at both the emission wavelengths 372 and $426 \mathrm{~nm}$, showed the maximum emission intensity with excitation wavelength of $267 \mathrm{~nm}$. These results indicate that the formation of the network in the HCz-based copolymers with DMSB should induce multiple energy states in the $\sigma-\pi$ interaction.

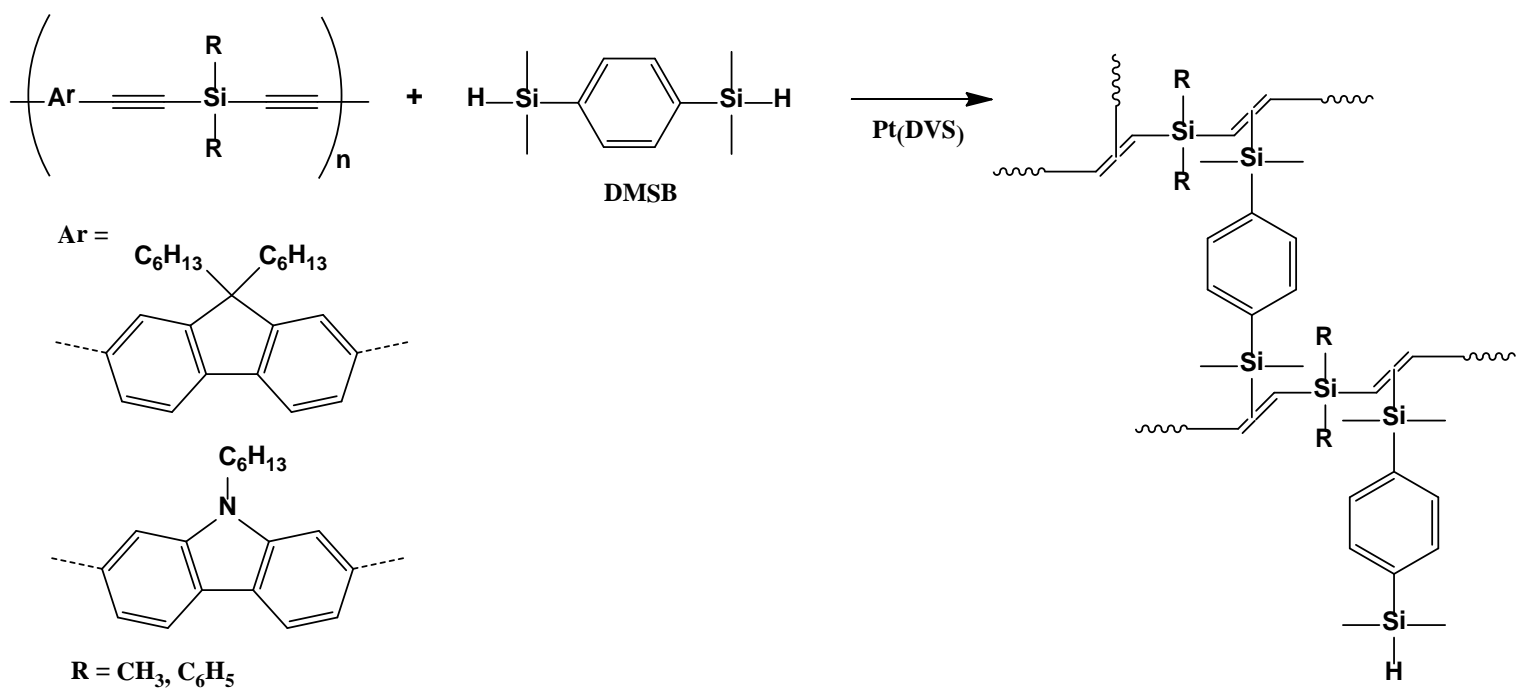

Scheme 3. Synthesis of HFl, HCz-based network cpolymers using a hydrosilylation reaction with DMSB.

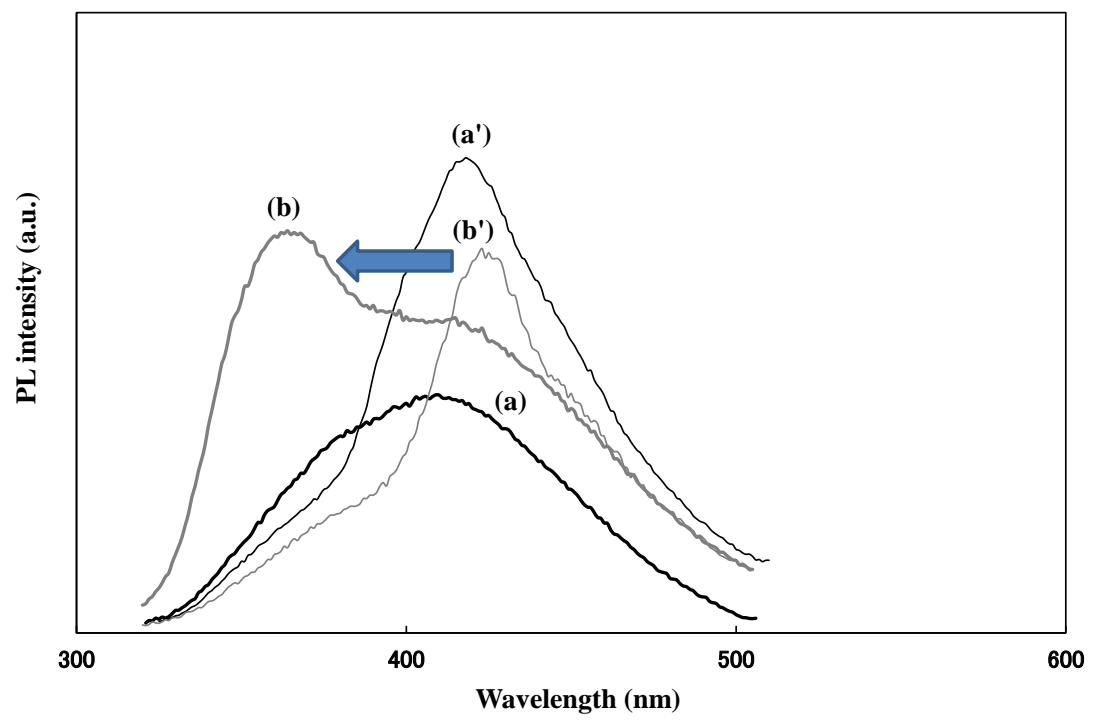

Figure 7. PL spectra of network polymers of (a) HCz-1, (b) HCz-2 with DMSB, and linear polymers (a') HCz-1, (B') HCz-2 (references) in chloroform solution, $\mathrm{HCz}$ unit: $10^{-8} \mathrm{~mol} / \mathrm{L}$. 
Table 4. Photophysical properties of HCz-based copolymers containing Si-unsaturated units in the main chain ${ }^{\mathrm{a}}$.

\begin{tabular}{cccc}
\hline Sample & $\begin{array}{c}\text { Degree of } \\
\text { Branching }^{\mathrm{b}}\end{array}$ & Absorption $^{\mathrm{c}}$ & ${\text { Solution, } \lambda_{\max }(\mathrm{nm})}^{\text {Emission }^{\mathrm{d}}}$ \\
\cline { 3 - 3 } HFl-1/DMSB & 0.50 & 276 & 415 \\
HFl-2/DMSB & 0.67 & $273(334,350)$ & 419 \\
HCz-1/DMSB & 0.66 & 267 & 419 \\
HCz-2/DMSB & 0.56 & $267(327,345)$ & $372(426)$ \\
\hline
\end{tabular}

${ }^{\mathrm{a}} \mathrm{HFl}, \mathrm{HCz}$ : repanting units $=0.41 \mathrm{mmol}, \mathrm{DMSB}=0.205 \mathrm{mmol}, \mathrm{Pt}(\mathrm{dvs})=10.4 \mu \mathrm{mol}(0.60 \mathrm{mM}$ of toluene solution $), 60 \mathrm{C}, 6 \mathrm{~h},{ }^{\mathrm{b}}$ Determined by ${ }^{13} \mathrm{C}$ NMR spectrum, bracket: shoulder peak, ${ }^{\mathrm{c}}$ Evaluated in chloroform $\left(10^{-5} \mathrm{~mol} / \mathrm{L}\right)$, bracket: shoulder peak, ${ }^{\mathrm{d}}$ Evaluated in chloroform (repeating unit: $10^{-8}$ $\mathrm{mol} / \mathrm{L})$, bracket: shoulder peak, emission was excited at $\lambda_{\max }$ of absorption.

\section{Conclusions}

The fluorene or carbazole-based alternating copolymers containing Si and ethynylene units in the main chain were successfully synthesized by Sonogashira coupling reaction of dibromo-fluornene or carbazole (HFl, $\mathrm{HCz}$ ) and diethynylene Si compounds (EMS, EPS). The copolymers showed good solubility in conventional organic solvents such as acetone, chloroform, THF, toluene, and dimethyl foramide. The resulting copolymers showed bimodal absorption peaks and broad emission peaks in the chloroform solutions derived from the intramolecular charge transfer through the $\sigma-\pi$ moiety. The emission peaks of the copolymers in the solid state showed remarkable blue-shift in comparison with those of the corresponding homo-polymers. The blue-shift in the emission peaks of the solid state copolymers should be induced by the higher energy states derived from intramolecular charge transfer through the $\sigma-\pi$ moiety in the copolymer. The phenomenon was not observed in the reference (co)polymers. The Si-ethynlene unit in the copolymers should play an important role for the specific molecular aggregation of the copolymers in the solid state. The hydrosilylation reaction of the ethynyl groups in the copolymers with DMSB yielded the branched copolymers, which were soluble in organic solvents. The reaction of HCz-based copolymers with DMSB induced the emission at short wavelengths in the chloroform solution.

The present copolymers should be one of the useful conjugated polymers with fluorescence features. The modifications and reactions of the unsaturated ethynyl groups in the copolymers would enable us to control the wavelength in the emission and to form the conjugated polymers with geometrical variations. As the next step, we are looking carefully into the molecular structure of the copolymers in the solid state. We are also trying to apply the copolymers as emission layers for LEDs, and the results will be reported elsewhere.

\section{References}

[1] Facchetti, A. (2011) $\pi$-Coujugated Polymers for Organic Electronics and Photovolatic Cell Applications. Chemistry of Materials, 23, 733-758. http://dx.doi.org/10.1021/cm102419z

[2] Saleh, M., Alam, J., Dass, L.A. and Raja, M. (2011) Recent Advances in Conjugated Polymers for Light Emitting Devices. International Journal of Molecular Science, 12, 2036-2054.

[3] Kim, H.K., Ryu, M.K. and Lee, S.M. (1997) Novel Silicon-Containing Poly(p-phenylenevinylene)-Related Polymers: Synthesis and Optical Properties. Macromolecules, 30, 1236-1239. http://dx.doi.org/10.1021/ma961295x

[4] Kwak, G. and Masuda, T. (2002) Poly(silyleneethynylenephenylene) and Poly(silylenephenyleneethynylenephenylene)s: Synthesis and Photophysical Properties Related to Charge Transfer. Macromolecules, 35, 4138-4142.

[5] Kim, H.K., Paik, K.L., Baek, N.S., Lee, Y. and Yoshino, K. (2003) Novel Silicon-Based Alternating Copolymers: Synthesis, Photophysical Properties, and Tunable EL Colors. Macromolecular Symposia, 192, 135-149. http://dx.doi.org/10.1002/masy.200390022

[6] Rao, T.V., Yamashita, H., Uchimaru, Y., Sugiyama, J. and Takeuchi, K. (2005) Pd-Catalyzed Hydrosilylation Polymerization of a Dihydrosilane with Diyne/Triyne Mixed Systems Affording Crosslinked Silylene-Divinylene Polymers and Their Properties. Polymer, 46, 9736-9741. http://dx.doi.org/10.1016/j.polymer.2005.08.052

[7] Yamashita, H., de Leon, M.S., Channasanon, S., Suzuki, Y., Uchimaru, Y. and Takeuchi, K. (2003) Palladium-Catalyzed Hydrosilylation Polymerization of Dihydro Silanes with Diyne Affording Silylene-Divinylene Polymers. Polymer, 55, 7089-7093. http://dx.doi.org/10.1016/j.polymer.2003.09.003

[8] Kitamura, N. and Yamamoto, T. (2004) Silicon-Containing Polymers or Oligomers for Electroluminescent Devices and Their Manufacture. JP2004-131700A. 
[9] Takagi, K., Tahara, A. and Kakiuchi, H. (2009) Synthesis and Light-Emitting Behavior of Silicon-Bridged Fluorene Copolymers Bearing Oligoarylenevinylene Chromophore. Polymer Journal, 41, 733-738. http://dx.doi.org/10.1295/polymj.PJ2009088

[10] Takagi, K., Kakiuchi, H. and Suzuki, M. (2006) Synthesis of Fluorene-Based Light-Emitting Polymers Bearing Silane Units and Their Opteolectornic Properties. Kohbunshi Ronbunsyu, 63, 663-669. https://www.jstage.jst.go.jp/article/koron/63/10/63_10_663/_pdf

[11] Kobayashi, N. and Kijima, M. (2007) Microporous Materials Derived from Two- and Three-Dimensional Hyperbranched Conjugated Polymers by Thermal Elimination of Substituents. Journal of Materials Chemistry, 17, 42894296. http://dx.doi.org/10.1039/b707925g

[12] Shao, K.F., Xu, X.J., Liu, Y.Q. and Yang, L.M. (2006) Blue Electrophosphorescent Light-Emitting Device Using a Novel Nonconjugated Polymer as Host Materials. Chemistry Letters, 35, 404-405. http://dx.doi.org/10.1246/cl.2006.404

[13] Fang, M.C., Watanabe, A. and Matsuda, M. (1996) Emission Spectra of $\sigma-\pi$-Conjugated Organosilicon Copolymers Consisting of Alternating Dimethylsilylene and Aromatic Units. Macromolecules, 29, 6807-6813. http://dx.doi.org/10.1021/ma960398c

[14] Kim, K.D., Park, J.S. and Kim, H.K. (1998) Blue Electroluminescence from Novel Silicon-Containing Poly(Cyanoterephthalylidene) Copolymers. Macromolecules, 31, 7267-7272. http://dx.doi.org/10.1021/ma980349v

[15] Naga, N., Tagaya, N., Noda, H., Imai, T. and Tomoda, H. (2008) Synthesis and Properties of Fluorene or CarbazoleBased Alternating Copolymers Containing Si and Vinylene Units in the Main Chain. Journal of Polymer Science: Part A: Polymer Chemistry, 46, 4513-4521. http://dx.doi.org/10.1002/pola.22788

[16] Naga, N., Ohkura, Y., Tagaya, N. and Tomoda, H. (2011) Synthesis and Chemosensing Behavior of Fluorene-Based Alternating Copolymers Containing Ether Side Chains and Si-Vinylene Units in the Main Chain. Journal of Polymer Science: Part A: Polymer Chemistry, 49, 4935-4940. http://dx.doi.org/10.1002/pola.24943

[17] Wang, F., Kaafarani, B.R. and Neckers, D.C. (2003) Synthesis of Silicon-Containing Unsaturated Polymers by Hydrosilylation Reactions. Photophysical Studies. Macromolecules, 36, 8225-8230. http://dx.doi.org/10.1021/ma034618f

[18] Kokil, A., Huber, C., Caseri, W.R. and Weder, C. (2003) Synthesis of $\pi$-Conjugated Organometallic Polymer Networks. Macromolecular Chemistry and Physics, 204, 40-45. http://dx.doi.org/10.1002/macp.200290054

[19] Kunai, A., Toyoda, E., Nagamoto, I., Horio, T. and Ishikawa, M. (1996) Polymeric Organosilicon Systems. 25. Preparation of Branched Polymers by Regiospecific Hydrosilylation of Poly[(silylene)diethynylenes] and Their Properties. Organometallics, 15, 75-83. http://dx.doi.org/10.1021/om950322p

[20] Sonntag, M. and Strohriegl, P. (2004) Novel 2,7-Linked Carbazole Trimers as Model Compounds for Conjugated Carbazole Polymers. Chemistry of Materials, 16, 4736-4742. http://dx.doi.org/10.1021/cm040142i 